\title{
IDENTIFICATION OF VIRULENT NEWCASTLE DISEASE VIRUSES IN BROILERS IN KAFRELSHEIKH GOVERNORATE THROUGH THE YEAR 2017
}

\author{
Abd Ellwahed El-Shawadfi ${ }^{*}$, Fares El-Khyat², AbdEI-Galil El-Gohary²
}

${ }^{1}$ General Organization of Veterinary Services, Ministry of Agriculture, Egypt. ${ }^{2}$ Department of Poultry\& Rabbits diseases, Faculty of Veterinary Medicine, Kafrelsheikh University, Egypt

*Corresponding author, E-mail: dr_abdelwahed1@yahoo.com

\begin{abstract}
The aim of the present study was to identify virulent Newcastle disease viruses (NDVs) circulating in broilers in Kafrelsheikh Governorate during the year 2017. Recognition of the virulent NDV strains to identify their degree of identity with the currently used vaccines against Newcastle disease in order to predict degree of protective immunity that can be offered by traditionally vaccines used against these virulent NDVs. The obtained results revealed presence of 11 samples positive for NDV as detected by inoculation into chick embryo via allantoic cavity route followed by $\mathrm{HA}$ and $\mathrm{HI}$ test. Furthermore, by using specific primers for $\mathrm{F}$ region to detect genotype VII, only 4 out of the positive 11 samples belonged to class II genotype VII sub genotype d were detected.
\end{abstract}

Key words: Newcastle disease virus; genotype VII; broilers; Egypt

\section{Introduction}

Newcastle disease (ND), a highly infectious viral disease targeting both wild and domestic bird species, was first detected in a poultry flock near the town Newcastle on Tyne (UK) (1). Newcastle disease virus (NDV), a member of the Paramyxoviridae family, is designated avian paramyxovirus serotype1. ND was first determined in Egypt by (2). According to virulence of NDV strain ND, the severity of the disease ranged $o$ from subclinical infection to death (3). Virulent NDV strains which belong to genotype VII sub-genotype $d$ are frequently isolated from Egyptian chicken farms causing severe economic loses especially in Kafrelsheikh Governorate (4). The pathogenesis of NDV depends on the virulence of the infecting virus and its tropism. The host to a large extent plays an important role in the virulence of NDV strains. Chickens are highly susceptible while ducks and geese may not show clinical signs when infected, even by lethal strains to chickens, in which the age, immune status of the bird, dose of the virus and route of exposure; nasal, oral, and ocular; appear to emphasize the respiratory nature of the disease (5). All these factors in addition to concurrent infection and environmental stressors go a long way to determine the course of the disease or infection (6).

Based on results obtained from phylogenetic analysis, it was postulated that gene mutations can induce conversion of the non or low virulent NDV strains into virulent or high virulent strains (7). Thus, percussions should be considered regarding the current applied diagnosis and control methods of ND, mainly due to enormous amounts of live vaccines used throughout the world (7). So, the detection of the NDV by virus isolation by inoculation in 
fertilized chicken eggs was still acting the prescribed method for the international trade and remained the method of choice for confirmatory diagnosis (8) and (9). Molecular detection of the F0 cleavage site sequence of NDV by PCR was used not only in characterization of NDV but also as a good predictor for NDV virulence (10).

Frequent occurrence of ND outbreaks in broiler flocks in Kafrelsheikh Governorate and the unknown sources of the virulent NDVs in these outbreaks were the integral factor to conduct this study. Therefore, this study aimed to recognize the new virulent NDV strains and compare the isolated sequences with those currently used in vaccines against ND. Consequently, these data could help us to achieve a perfect immune response. In the present study, we also used conventional methods and modern molecular techniques for accurate diagnosis of NDV

\section{Materials and methods}

\section{Samples, inoculation, $H A$ and $H I$}

Spleen, liver, trachea, lung and cecal tonsils were collected from sick birds from 50 suspected flocks located at Kafrelsheikh governorate. Samples from each individual flock were pooled together. Pooled samples were minced and diluted with phosphate buffered saline $10 \%$, centrifuged and used for inoculation of 10 days chick embryo via allantoic cavity route (11). Allantoic fluid was harvested after 3 days, kept at -20 until tested by HA followed by HI test using 96 well microtiter plates and reference antisera (8). The HI endpoint was determined as the highest dilution of the serum that causing complete inhibition of HA activity of 4HA unit of antigen.

\section{Rreal time PCR ( $q P C R)$}

qPCR (F-assay)-was performed according to (12), to detect virulent NDVs dependant on the amino acid sequence around this site 112-117 of the F gene using the following oligonucleotide primers and probes.

\section{Forward:}

F+4839 TCCGGAGGATACAAGGGTCT
Reverse:

F-4939 AGCTGTTGCAACCCCAAG

Probe

$F+4894$

[FAM]AAGCGTTTCTGTCTCCTTCCTCCA[TAMRA]

\section{Molecular diagnosis using RT-PCR}

Before sequencing the positive isolated strains detected by qPCR, we performed reverse transcription PCR (RT-PCR) to prepare F gene for sequencing. This was conducted using the following primer sequences: NDV-M2: 5' TGGAGCCAAACCCGCACCTGCGG-3' and NDV-F2: 5'-GGA GGA TGT TGG CAG CATT-3' as previously described (13). The PCR products were visualized by $1.5 \%$ agarose gel electrophoresis. Two ways sequencing was carried out by MacroGene Company, South Korea and the obtained sequences were annotated and analyzed by Geneious software version 4.6 .4 (14).

\section{Results}

Inoculation of the 50 specimens in fertilized chick eggs resulted in 12 positive allantoic fluid samples as detected by slide hemagglutination agglutination (HA) test. The hemagglutination inhibition $(\mathrm{HI})$ test revealed that 11 out of 12 allantoic fluid samples were positive for NDV (Table 1).

The qPCR (F-assay) for detection of virulent NDV revealed that only $4(1,5,10,11)$ out of 12 farms were positive as compared to the control FAM 18.93 with amplification plots 19.3232.5. This indicates that these positive samples were virulent NDV isolates. While the other 8 farms $(2,3,4,6,7,8,9,12)$ were non virulent NDV isolates. (Table 2). The virulence depended on the theory of amino acid sequences in F0 at the site of 112-117 in which at least three basic amino acids at the position of residues 113 to 116 and phenylalanine $(F)$ at 117 are present (10)

Before sequencing we isolated $\mathrm{F}$ gene (that encoded F-protein including the F0 cleavage site) using RT-PCR and positive samples gave PCR products with size of 109 bp similar to positive control samples (Fig.1). After sequencing, we found 2 virulent NDV isolates 
NDV/Egypt/Kafrelsheikh1/2017

NDV/Egypt/Kafrelsheikh 2/2017 strains (these sequences were deposited in GenBank databases) which both related to the genotype VII sub-genotype d. Similarly, (15) also determined genotyping of NDV isolates using the same gene.

Comparing nucleotide sequence of F-protein encoding gene of

NDV/Egypt/Kafrelsheikh1/2017

NDV/Egypt/Kafrelsheikh2/2017 isolates with some isolated virulent NDV outbreaks strains showed clustering of the two Egyptian isolates with the very virulent NDV strain

NDV/Chicken/China/sdwf07/2011, NDV/Chicken/China/sdwf07/2011, EG/CK/NDV/16/Luxor.Esna/2011 and NDV/EG/CK/101/2012. Also, they were clustered with recent very virulent NDV strains NDV-F388-RLQP-CH-EG-14,

NDV/Dove/Desouk/Egypt/MSS/2015 and Chicken/Israel/555/2015 (Fig. 2). All these strains belonged to genotype VII sub genotype $\mathrm{d}$ as agreed and confirmed by previous studies (4), (16) and (17).

Table 1: Result of NDV identification after the inoculation in fertilized chick eggs

\begin{tabular}{lllll}
\hline Total samples & $\begin{array}{l}\text { +ve samples } \\
\text { to HA test }\end{array}$ & $\begin{array}{l}\text {-ve samples } \\
\text { to HA test }\end{array}$ & $\begin{array}{l}\text { +ve samples } \\
\text { to HI test }\end{array}$ & $\begin{array}{l}\text {-ve samples } \\
\text { to HI test }\end{array}$ \\
\hline 50 & 12 & 38 & 11 & 1 \\
- & $24 \%$ & $76 \%$ & $22 \%$ & $2 \%$ \\
\hline
\end{tabular}

Table 2: Result of qPCR (F- assay) for detection of virulent NDVs

\begin{tabular}{|c|c|c|c|}
\hline Well Name & Dye & $C t(d R n)$ & \\
\hline Pos & FAM & 18.93 & \\
\hline 10 & FAM & 22.01 & \\
\hline 5 & FAM & 25.81 & \\
\hline 1 & FAM & 23.57 & \\
\hline 11 & FAM & 29.78 & \\
\hline Neg & FAM & $\mathrm{No} C t$ & \\
\hline 8 & FAM & $\mathrm{NoCt}$ & \\
\hline 12 & FAM & $\mathrm{No} C t$ & \\
\hline 2 & FAM & $\mathrm{No} C t$ & \\
\hline 6 & FAM & $\mathrm{No} C t$ & \\
\hline 3 & FAM & $\mathrm{NoCt}$ & \\
\hline 7 & FAM & $\mathrm{NoCt}$ & \\
\hline 9 & FAM & $\mathrm{No} C t$ & \\
\hline 4 & FAM & $\mathrm{No} C t$ & \\
\hline \multicolumn{3}{|c|}{ Assays shown } & Well types sho \\
\hline Figh & & FAM & $\longdiv { \text { Unknown } }$ \\
\hline
\end{tabular}

Pos (+ve) fam indicate vinulent strain while Neg (-ve) fam indic ate non vinulent strain. 


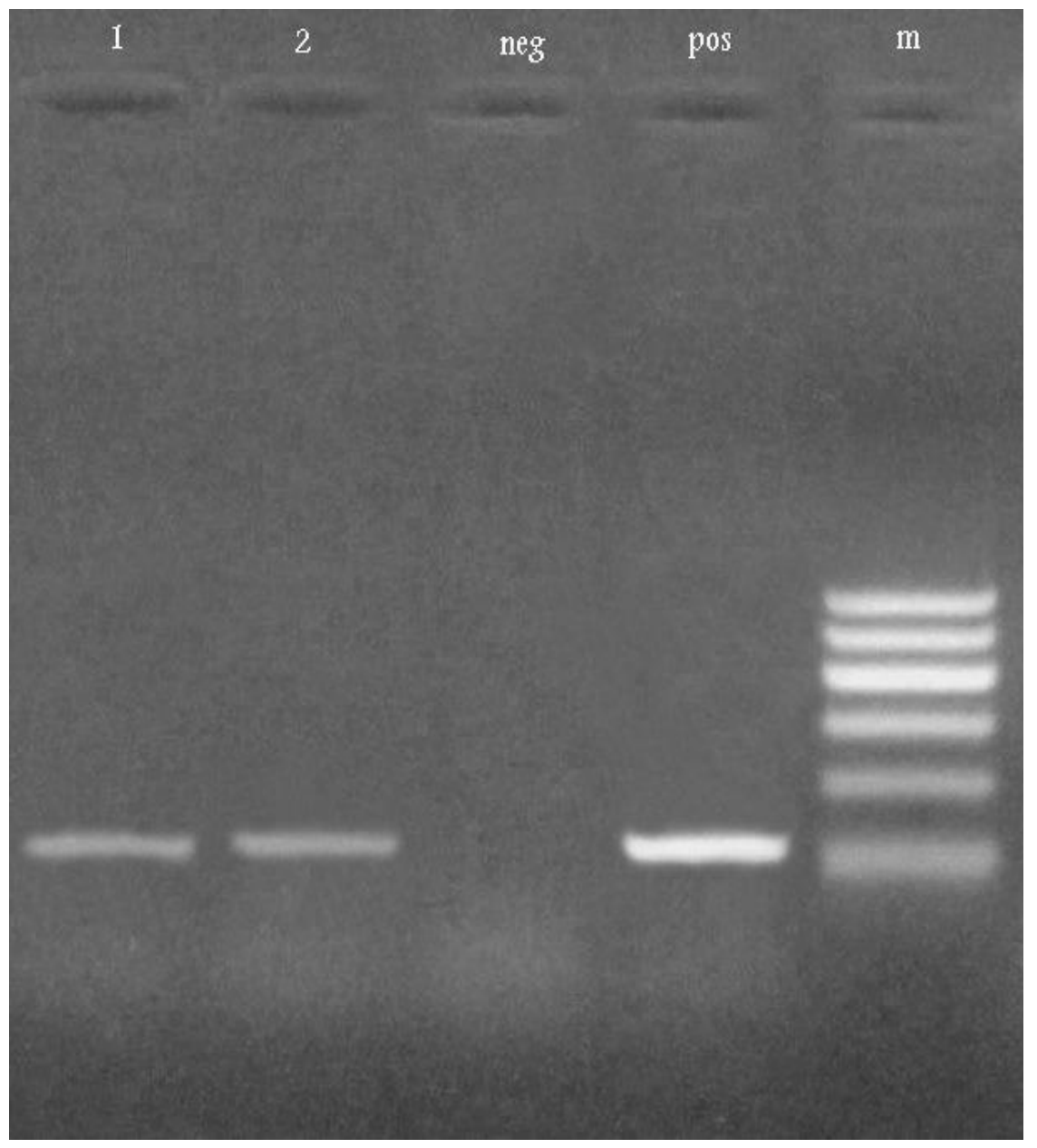

Figure 1: Ethidium bromide agarose gel electrophoresis of the RT-PCR products (109 bp). 1 and 2 were the isolated virulent NDV strains, neg: negative control, pos: positive control, M: marker (100 bp) 


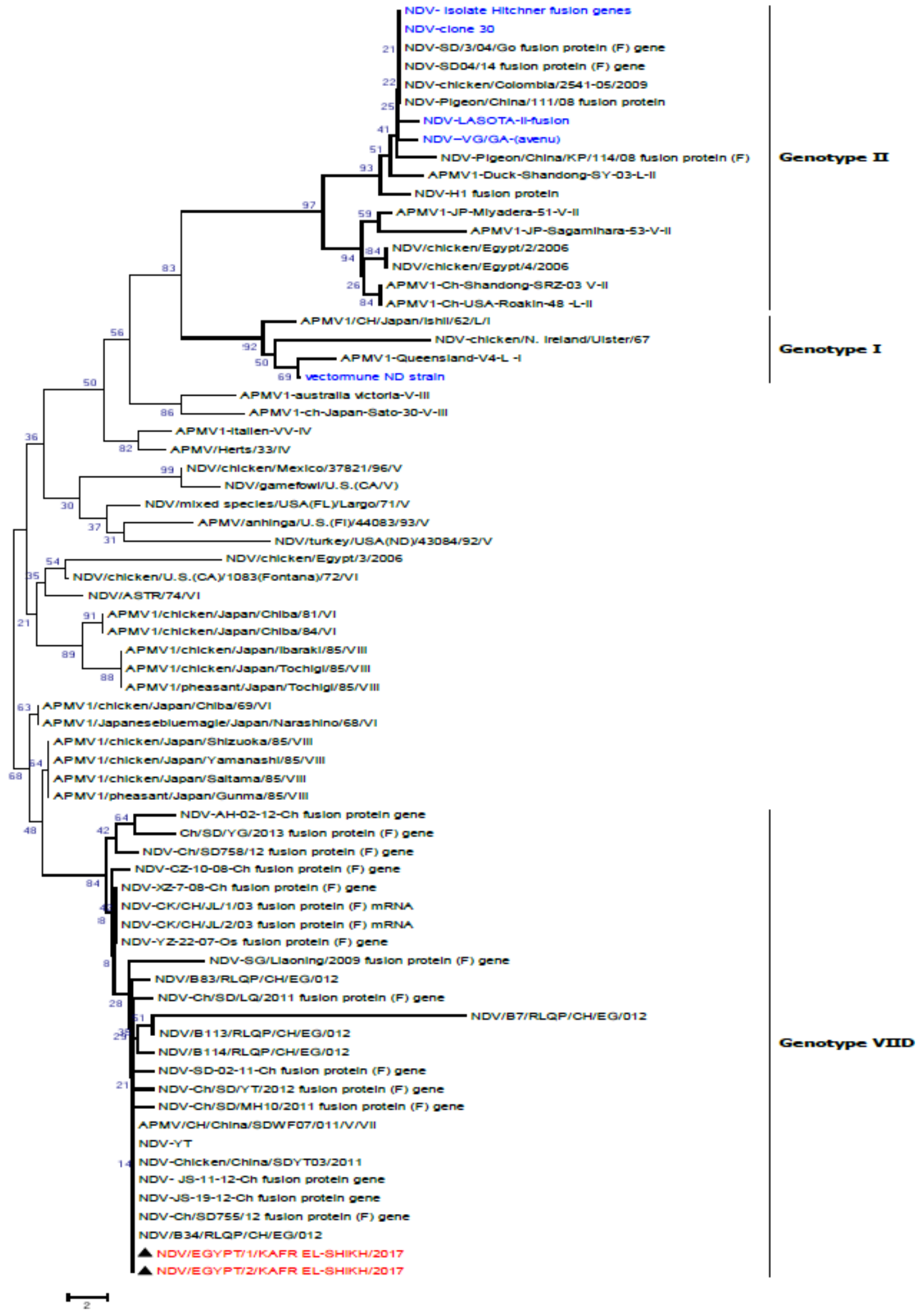

Figure 2: The phylogenetic tree of neighbor joining phylogenetic analysis based on nucleotide sequence clustering of F- gene of genotype VII subtype d 


\section{Conclusion}

The obtained results revealed that Egyptian chicken contained virulent NDV strains, especially class II genotype VII sub genotype d, which may be associated with severe economic losses of ND in Egypt in general and in Kafrelshiekh Governorate in particular.

\section{References}

1. Doyle T M. A hither to unrecorded disease of fowls due to filter passing virus. J. Comp. Pathol 1927; 40:144-69.

2. Daubney R and Mansi W. The occurrence of Newcastle disease virus in Egypt. J. Comp. Pathol 1947; 58: 189-200.

3. Ballagi A, Wehmann E, Herczeg J, Belfik S, and Lomniczi B. Identification and grouping of Newcastle disease virus strains by restriction site analysis of a region from the F gene. Arch Virol 1996; 141:243 -61.

4. Radwan MM, Darwish SF, El-Sabagh IM, ElSanousi AA, Shalaby MA. Isolation and molecular characterization of Newcastle disease virus genotypes II and VIId in Egypt between 2011 and 2012. Virus Genes 2013; 47(2):311-6.

5. Beard CW and Easterday B C. The influence of route of administration of Newcastle disease virus on host response. J Infect Dis 1967; 117:55-70.

6. Higgins D A. Nine disease outbreaks associated with myxoviruses among ducks in Hong Kong. Trop Anim Health Prod 1971; 3:232-40.

7. Westbury HA. Virulent Newcastle disease in Australia: molecular epidemiological analysis of viruses isolated prior to and during the outbreaks of 1998-2000. Virus Res. 2001; 77 (1), 51-60.

8. Young M, Alders R, Grimes S et al. Controlling Newcastle Disease in Village Chickens: A Laboratory Manual. ACIAR Monograph 2002; 87 : 142-9.

9. Alexander DJ and Senne DA. Newcastle disease and other avian paramyxoviruses: A laboratory manual for the isolation, identification and characterization of avian pathogens, $5^{\text {th }}$ edition, 2008; 135-41.

10. Miller PJ, Decanini EL and Afonso CL. Newcastle disease: Evolution of genotypes and the related diagnostic challenges. Infect. Genet. Evol. 2010; 10 (1), 26-35.

11. Pollard JW and Walker JM. Methods in molecular biology: Plant cell and tissue culture. $\mathrm{Hu}-$ mana Press, Totowa 1997; 6: 129-39.

12. Wise MG, Suarez DL, Seal BS et al. Development of a Real-Time Reverse-Transcription PCR for Detection of Newcastle Disease Virus RNA in Clinical Samples. Journal of Clinical Microbiology 2004; 42 (1): 329-38.

13. Mase M, Imai K, Sanada Y et al. Phylogenetic analysis of Newcastle disease virus genotypes isolated in Japan. J. Clin. Microbiol. 2002; 40: 3826-30.

14. Orabi, A., Hussein, A., Saleh, A.A., ElMagd, M.A., Munir, M., 2017. Evolutionary insights into the fusion protein of Newcastle disease virus isolated from vaccinated chickens in 2016 in Egypt. Archives of Virology 162, 3069-79.

15. Aldous EW, Mynn JK, Banks J and Alexander DJ. A molecular epidemiological study of avian paramyxovirus type 1 (Newcastle disease virus) isolates by phylogenetic analysis of a partial nucleotide sequence of the fusion protein gene. Avian Pathol. 2003; 32:239-57.

16. Hussein HA, Emara MM and Rohaim MA. Molecular Characterization of Newcastle Disease Virus Genotype VIID in Avian influenza H5N1 Infected Broiler Flock in Egypt. International Journal of Virology 2014; 10 (1): 46-54.

17. Sultan S, Osman N, Ahmed A, Ibrahim R and Sabra M. Phylogenetic Characterization of Velogenic Newcastle Disease Viruses Isolated from Field Outbreaks among Vaccinated broiler chickens in Upper Egypt. Assiut Vet Med J 2015; 61: 126-35. 